\title{
Morphological Changes in Heart Tissue When Exposed to Pulsed Currents in Chronic Purulent Pneumonia (Experimental Study)
}

\section{Sadykova GA*, Rakhmatullaev HU, Zalyalova ZS, Akhmedov MA and Alimov IM}

Republican Specialized Scientific and Practical Medical Center of Therapy and Medical Rehabilitation and Tashkent Institute of Advanced Medical Training and Tashkent Institute of Chemical Technology, Tashkent, Uzbekistan

*Corresponding Author: Sadykova GA, Republican Specialized Scientific and Practical Medical Center of Therapy and Medical Rehabilitation and Tashkent Institute of Advanced Medical Training and Tashkent Institute of Chemical Technology, Tashkent, Uzbekistan.
Received: March 09, 2020

Published: April 01, 2020

(c) All rights are reserved by Sadykova GA., et al.

\begin{abstract}
A model of experimental chronic purulent pneumonia was induced in mongrel white rats. Morphological changes in the heart tissue were manifested by uneven hypertrophy of cardiomyocytes, thickening of vascular walls and increasing their quantitative ratio, moderate growth of connective tissue layers in perivascular zones, intermuscular edema with impaired blood circulation of the muscle wall. When electromyostimulation with pulsed currents of respiratory muscles in the heart tissue revealed dystrophic swelling and focal dilution of cardiomyocytes, uneven inter-daily edema, hypertrophy of the walls of arterioles, full blood, circulatory disorders in the form of focal hemorrhages in the myocardium and epicardium.

Keywords: Chronic Purulent; Inflammation; Tissue; Heart; Morphology; Experiment; Laboratory Animals; Pulse Currents; Electromyostimulation
\end{abstract}

\section{Introduction}

Chronic Obstructive Pulmonary Disease (COPD) is considered as one of leading diseases of morbidity among the population of the world. The disease progresses rapidly, leading to early disability of patients, thereby causing significant economic and social damage [1]. Due to pneumonia, the cardiovascular system stops functioning properly, worsening the prognosis of recovery.

Pathomorphological changes in the heart with COPD and pulmonary hypertension are characterized mainly by 2 types of changes. For the first (hypertrophic-hyperplastic) type is characterized not so much by dilatation as by hypertrophy of the right ventricle of the heart. In the second type of restructuring, there is a combination of myogenic dilatation of the right ventricle with myocardial hypertrophy and, less commonly, with expansion of the left ventricle cavity. Atrophic-sclerotic processes predominate in the muscle fibres of the right ventricle. The endocardia fibroelastosis is expressed in the right atrium and right ventricle. The muscle fibres in the left ventricle are not changed or predominate their hypertrophy, and cardiosclerosis has a large-scale character feature and is signed only in the presence of concomitant diseases (arterial hypertension, atherosclerosis) [1].

The major reason of death in COPD is recognized as the development of severe respiratory and pulmonary heart failure [3-7].

\section{Objective of the Research}

To study the morphology of heart tissue in experimental chronic purulent inflammation of the lungs (e-CPI) during electromyostimulation of respiratory muscles by pulsed currents.

\section{Materials and Methods}

20 outbred white rats - males weighing 180 - 200g were examined. Test rats were divided into 2 groups. In the first group were examined healthy rats. In the second group were examined rats with model of e-CPI. The model was reproduced by the method of Batyrova ZB and Shamirzaeva NH [2], which is based on prolonged mechanical intra-trachea-bronchial irritation of the respiratory tract. In the conditions of sterile, under local novocaine anaesthesia, a longitudinal incision was made along the midline on the anterior surface of the neck of the animal $1.5-2.0 \mathrm{~cm}$ long. After exposure of the anterior wall of the trachea between its rings, a capron thread with a diameter of 0,4 mm, up to $8-10 \mathrm{~cm}$ long was inserted. In this case, the distal end of the thread was in the lumen of the trachea, and its proximal end was fixed on the skin. The wound was sutured in layers tightly. After 30 - 45 days from the beginning of the experiment, the fixing nylon thread was cut and removed with the help of tweezers. Slaughter of animals was carried out by instant decapitation on 30 - 45 days from the moment of reproduction.

For morphological researches, the taken pieces of the diaphragm and lung tissue, taken after slaughter, were fixed in a 10\% solution of neutral formalin. Paraffin histological sections 5 - 6 mg 
thick were stained with haematoxylin eosin. Microscopy of the preparation was carried out under an optical microscope XS-213 and a microscope from Leica.

In the second group, on the 45th day from the start of the experiment with e-CPI, the electromyostimulation of respiratory muscles was performed by pulsed currents. The apparatus "Stimulus-1" was used (Figure 1). On the pre-treated skin surface of eCPI along the mid-axillary line bilaterally at the level of 7 - 8 ribs, electrodes $1.5 \times 1.3 \mathrm{~cm}$ in size were fixed with gaskets (Figure 2). To four rats in this group, current was supplied in a constant mode, and separately to 4 rats in a variable mode. The current strength is $0.1 \mathrm{~mA} / \mathrm{cm}^{2}$, the frequency is $2.5-5.0 \mathrm{~ms}$. For 5 minutes, e/d, No. 9 procedures.

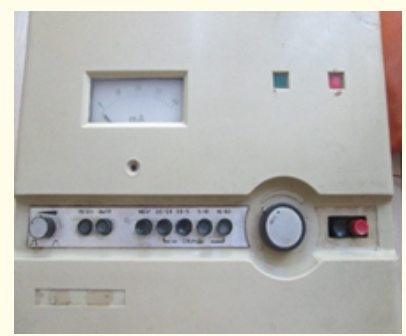

Figure 1: The apparatus "Stimulus-1" (in usual or changeable regime).

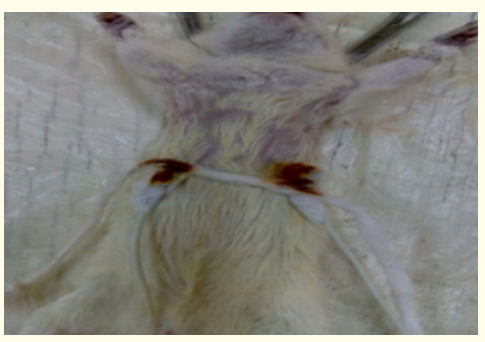

Figure 2: The electrodes are fixed bilaterally along the mid-axillary line at level 7 of the intercostal space at e-CPI.

\section{Results and Discussion}

Macroscopic picture of the e-CPI: Not collapsed lung, in places pale gray-red or dark red color, dough consistency, under the pleura and parenchyma found small hemorrhages. On a section of the lumens and transected bronchi extruded and flows foamy cloudy liquid, sometimes colored in pink.

The morphological picture of the heart in rats in the control group of animals is characterized by unexpressed hyperemia of the tissue (Figure 3).

In rats with an experimental model of e-CPI, the following morphological changes prevailed in the heart (Figure 4). In the heart, in comparison with the control group of animals, uneven hypertrophy of cardiomyocytes, thickening of the walls of blood vessels and an increase in their quantitative ratio were observed.

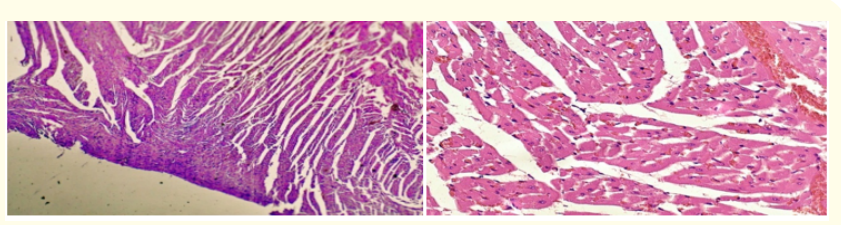

Figure 3: The heart of the rat control group. Hyperemia of the tissue. Gone. 10x10, 10x20, 10x40. Hematoxylin-eosin stain.

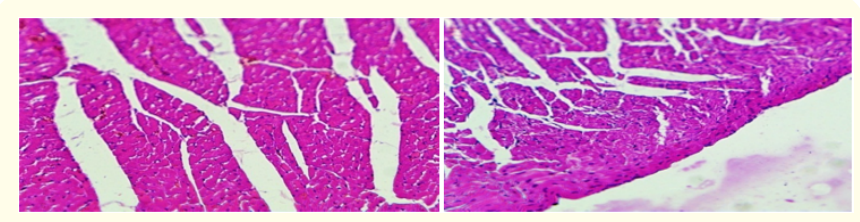

Figure 4: Heart, experimental animal 1. Interlayers of delicate connective tissue in the perivascular and intramuscular sections, intermuscular edema. Gone. 10x10,10x20. Coloring hematooclisin-eosin.

The moderate proliferation of connective tissue layers in the perivascular zones, intramuscular edema was also determined (Figure 5 and 6).
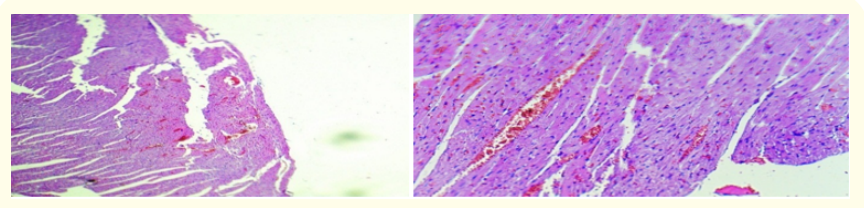

Figure 5: Heart, experimental animal 2. Hyperemia of the tissue, focal perivascular erythrodiapedes. Gone. 10x4, 10x10. Hematoxylin-eosin stain

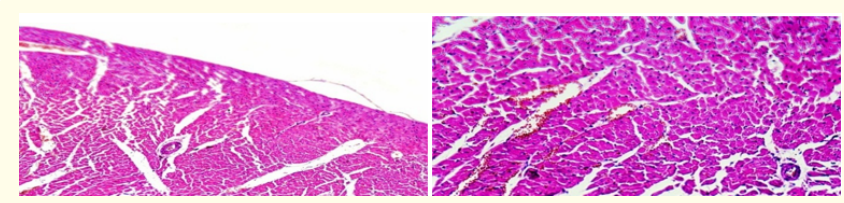

Figure 6: Heart, experimental animal 4. Hypertrophy of the walls of the arethriol. 10x4, 10x10. Hematoxylin-eosin stain.

\section{Conclusion}

Thus, long-term mechanical irritation of the bronchi causes, along with chronic purulent inflammation of the lungs, morphological changes in the heart tissue indicating the inclusion in the inflammatory process in e-HVL along with the lung tissue and heart tissue with cellular shifts in them. Pulse currents in this dosage cause circulatory disorders in the form of focal changes in cardiomyocytes

The research is still continuing. 


\section{Bibliography}

1. Global strategy for the diagnosis, treatment and prevention of chronic obstructive pulmonary disease (revised 2011) translated from English, edited by AS Belevsky. M-Russian Republican society 2012: 80, Il. COPD: Morphological picture. Edited by AG Chuchalin from 16.02-2008, 21: 35.

2. Batyrova ZB and Shamirzaev NH. Method for modeling chronic non-specific lung inflammation (Certificate v 20420502 a 2).

3. Landysheva IV and S Yu Landyshev. "Chronic pulmonary heart". Blagoveshchensk (2001): 140.

4. Sadykova GA., et al. "Morphological changes of the diaphragm in chronic purulent inflammation of the lungs (experimental study)". Therapeutic Bulletin of Uzbekistan, Tashkent 4 (2018): 53-57.

5. Shmelev EI. "Chronic obstructive pulmonary diseases and chronic pneumonia. Terminological and clinical aspects". Rus Honey Journal 12 (2000): 487-491.

6. Debigaru R. "Ubiquitination and proteolysis in limb and respiratory muscles of patients with chronic obstructive pulmonary disease". Proceedings of the American Thoracic Society 7.1 (2010): 84-90.

7. Sadykova GA., et al. "Morphological changes of the diaphragm in chronic purulent pneumonia (experimental study)". Acta Scientific Medical Sciences 3.3 (2019): 60-63.

\section{Assets from publication with us}

- Prompt Acknowledgement after receiving the article

- Thorough Double blinded peer review

- Rapid Publication

- Issue of Publication Certificate

- High visibility of your Published work

Website: https://www.actascientific.com/

Submit Article: https://www.actascientific.com/submission.php Email us: editor@actascientific.com

Contact us: +919182824667 